\title{
Contemporary Cultural Studies and the Evolutionary Development of Literature and Art
}

\begin{abstract}
Xu Chao
Rizhao Polytechnic, Shandong Rizhao, 276800

Keywords: Cultural studies; trends of thought; literary and artistic disciplines

Abstract: The stirring of the cultural research trend to the contemporary art discipline is an academic subject which is easy to arouse the researcher's desire to explain, but also quite difficult and challenging. This paper takes this as the main research object. Facing the trend of thought of cultural research that has swept inland China for a short time, this paper tries to grasp its origin, deeply interpret the essence, attributes and research paradigms of cultural research, and further explore the impact of this trend of thought on knowledge production, theory construction and method renewal of literary and artistic disciplines on the basis of this, so as to explore the impact of this trend of thought on literary and artistic disciplines, the evolution and expansion of literature and art in the new historical context.
\end{abstract}

At present, the research results in the cross-field of cultural research and literature and art are very limited. There are many cries and appeals in theory, but few in practice. Literature and art can absorb the theoretical discourse and methodology needed for its own development from the trend of thought of cultural studies. Many scholars are also advocating to find a way out of the encirclement of literature and art from cultural studies. However, the reality is that the collusion relationship between the two has been expounded much in theory, but few achievements have been found in practice, and few scholars have considered the evolution of the discipline in the field of literature and art.

\section{Value Orientation of Contemporary Chinese Cultural Development}

In the cultural pursuit for over a century, the relationship between traditional culture and modernization constitutes a main line for Chinese people to explore the road of cultural development. Although people differ greatly and advocate different ideas, the general cultural trend is the same, that is, to take modernization as the goal and move towards modern industrial civilization. However, China's modernization process has lagged behind that of Western countries. Western developed countries have entered the post-modern stage of development. Post-modern culture has also poured into China in the wave of reform and opening up. When the countercultures of ore-modern, modern and post-modern interweave and present, our cultural orientation is particularly important. As shown in Table 1. 
Table 1 Value Orientation of Contemporary Chinese Cultural Development

\begin{tabular}{|l|}
\hline \multicolumn{1}{|c|}{ Value Orientation of Contemporary Chinese Cultural Development } \\
\hline 1. Dual Cultural Background \\
\hline 2. Modernization Direction of Culture \\
\hline
\end{tabular}

\subsection{Dual Cultural Background}

In contemporary Chinese society, which is about to cross the 21st century, there are various cultural trends of thought. In terms of the general trend, they can be classified into three categories: first, traditional or ore-modern cultural trends of thought. The traditional culture with Confucianism, Taoism, Law and Buddhism as the mainstream still has a deep influence on the development of contemporary Chinese society and culture. This kind of traditional culture was formed and developed on the basis of patriarchal hierarchical society with blood relationship as its link. Its basic value orientation was loyalty to the monarch, hierarchical concept, righteousness of rivers and lakes, karma, etc. Second, the cultural trend of thought aiming at the development of modernization.

This trend of thought is mainly formed and developed around the May 4th Movement. Its basic value orientation is to respect rationality, personality and personality, advocate equality, freedom and democracy, and advocate scientific knowledge and scientific spirit. Thirdly, the post-modernist trend of thought with the purpose of criticizing modernity. In the West, it rose in the sixties and seventies, and made great progress in the eighties and nineties and spread to China. The basic value orientation of this trend of thought is to advocate irrationality, criticize science and technology and democratic politics, deconstruct truth and ideals, and pursue the state of play.

\subsection{Modernization Direction of Cullture}

From the perspective of theoretical comprehensiveness and long-term social development, China's cultural studies should take into account both the above-mentioned dual tasks. However, from the urgency of Chinese cultural construction, the focus of cultural construction should be positioned on the conscious promotion of modern culture. Because at the level of basic human behavior and cultural mode, China has not completely surpassed the form of agricultural civilization, and is still in the period of transformation from agricultural civilization to industrial civilization. Therefore, aiming at the development of modernization and replacing experiential culture with rational culture should be the basic orientation of our cultural construction in the transitional period. Moreover, to construct a modern rational cultural model, it is important to find out the focus of cultural construction. We should not only highlight the epochal nature of culture, embody the scientific spirit and democratic spirit of modern culture, but also pay attention to the development and excavation of the advantages of our national culture and establish a cultural style suitable for the development of China's modernization.

\section{The Absorption of Cultural Objects in Literature and Art}

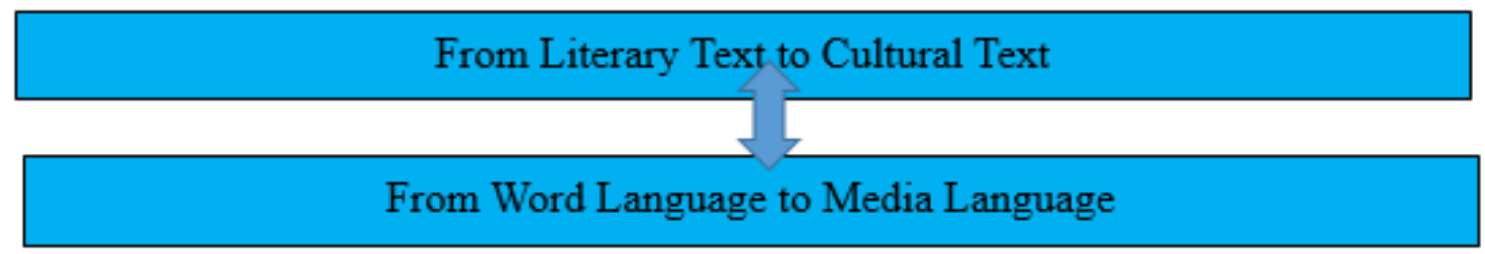

Figure 1.The Absorption of Cultural Objects in Literature and Art 
As shown in figure 1, a detailed analysis is presented below.

\subsection{From Literary Text to Cultural Text}

In the context of modern cultural criticism, the broad sense of text refers to any symbol or symbol chain that people can understand and interpret. A picture, a melody, a scene, a ceremony, even a set of fashion, a gesture are all regarded as texts. The "text" here includes not only written texts (such as publications, literature, etc.), but also visual texts, such as movies, advertisements, music, photography, broadcasting, etc. At the same time, it also includes other kinds of symbolic artifacts (such as fashion). These texts will be clearly depicted in our research field. Therefore, it is important to define some key issues related to texts and life experiences. This clearly refers to the consumers of these texts.

Unlike the works in the four elements of literature, the text transcends the literary threshold and is applied in a broader context of cultural criticism. Cultural text is an interdisciplinary field of many disciplines. In order to achieve academic goals, sociology may also regard cultural texts as research objects, and one of the interdisciplinary fields of literary and cultural studies is cultural texts. We still define literary and artistic studies in the sense of literature, but the extension of literary and artistic studies has expanded. It is no longer confined to sportswriters and literary phenomena, but encouraged to expand into daily life. As for the limits of expansion, it will take some time to consider.

\subsection{From Word Language to Media Language}

The way literature exists keeps pace with the times, and it changes constantly with the corresponding innovation of communication technology. Literature originally existed in the form of oral literature handed down orally. In China, there were "evil promises" in the labor theory about the origin of literature (contained in "Lithuanian Tao Undying"), and then words engraved on cave walls, bell tripod and utensils, which was the way of literary existence in the "ore-printing era". The popularization and high development of printing media brought about the unprecedented prosperity of literature. Literature, as we generally call it, is also a paper-based form of writing in the form of print media.

\section{Absorption of Cultural Research Methods and Paradigms from Literature and Art Disciplines}

\subsection{Text Political Analysis}

Compared with the appearance of text politics in cultural studies, the analysis of text politics in literary and artistic studies has always been in a state of escape or absence. The relationship between literature and art and politics is always inseparable. Literature and art once depended on politics. As a result, the way of constructing knowledge system in accordance with the law of literature development was blocked. Therefore, in the new era, literature and art should get rid of the status of "political slave" and "class analysis tool", and break away from the ideological pressure. For a long time, the political dimension has been stripped and isolated from the literary palace. Even when it comes to the essence of literature, it is also defined as aesthetic ideology to illustrate the distance between literature and politics. The whole 1980s was a period of alienation between literature and politics. Literary and artistic theorists, along the track of linguistics, were carrying forward the inward turn of literary and artistic theories and analytical methods, slowing down their pace when they encounter the "literariness" of formalism. 


\subsection{Research methods of Ethnography}

\subsubsection{Ethnography of Culltural Studies: Strategies for Reproduction}

Ethnography of cultural studies has achieved a kind of ethnic group research which is dissolving in the life of the object of study. It can not only study the other cultures of different nationalities and places, but also reproduce the life of the nation, class, community and group, and seek the subject of difference or resistance within the whole.

\subsubsection{Ethnography of Literature and Art: Intervention in Literary Life}

The ethnographic study of "literary life" has a long way to go. Steady and steady style of study is the basic requirement for researchers. More importantly, it is necessary to have the ability of cross-domain analysis, and be able to break the research model and method of trauma. Generally speaking, theoretical Chinese researchers are not good at practical social surveys. However, reliable data is an essential part of the research. Therefore, if we want to break the boundaries of the field, cultural research can be called a shortcut.

Literary activity itself is a special cultural practice, which is the most profound influence of cultural studies on literary concepts. The application of ethnographic methods to literary life is an intervention strategy of literary knowledge discourse renewal and reappearance, which lies outside the literary text and inside the literary world. If the structure, form and content of literary texts mean "internal research" stipulated by traditional literature and art, then literary life is another kind of "internal research" defined from the perspective of ethnography. That is to say, the theoretical interpretation object of literary and art is no longer only an aesthetic structure related to the pure art field, but also a real process of literary activities occurring in social life. The statement of this process indicates the close contact between ethnography and literature.

\section{Conclusion}

Literature and art has been in the process of evolutionary development. The evolution of disciplines plays an important role in the production and innovation of knowledge. Modern disciplines have brought explosive accumulation of knowledge in geometric form, and they themselves have been moving from single type to synthesis. Literature and art has been evolving in the short and long history of discipline development. It has not been obvious and potentially developed in a period of history. However, due to the trigger of cultural research trend, the comprehensive research ability of literature and art has gradually emerged. When the theoretical framework of literature and art discipline itself is insufficient to fully incorporate the internal knowledge system, the implosion of knowledge and the disciplinary wall. When the tension between the original knowledge and the subject disappears due to the bursting of base, the discipline will realize its own evolution in the way of renewing the knowledge system.

\section{References}

[1] Tao Dongle. Reflections on the construction of literary knowledge in the perspective of sociology [J]. Literary Review, 2007 (5).

[2] Tong Binning. How should the boundary of literature and art move [J]. Hebe Academy Journal, 2004 (4).

[3] Thu Li yuan. Reflections on the Reflection and Construction of Current Literature and Art Disciplines [J]. Literary Review, 2006 (3).

[4] Thu Li yuan ET AL. Reflections on the theory of "cultural research turn" in literature and art [J]. Journal of Tianjin Normal University, 2005 (3).

[5] Ian Zhengzhou. Thirty years of literary theory - from the new era to the new century [J]. Literary and artistic contention, 2007 (3). 